\title{
PENGARUH MOTIVASI DAN GAYA KEPEMIMPINAN TERHADAP KINERJA PEGAWAI PADA KANTOR DINAS PERINDUSTRIAN DAN PERDAGANGAN PROVINSI SULAWESI SELATAN
}

\author{
Idham Mulyadi \\ idhammulyadi@unismuh.ac.id \\ Fakultas Ekonomi dan Bisnis \\ Universitas Muhammadiyah Makassar \\ Muh Ikram Idrus \\ muhikramidrus@gmail.com \\ Fakultas Ekonomi dan Bisnis \\ Universitas Muhammadiyah Makassar \\ Muh Akib Agussalim \\ muhakibagussalim@unismuh.ac.id \\ Fakultas Ekonomi dan Bisnis \\ Universitas Muhammadiyah Makassar
}

\begin{abstract}
This study aims to analyze the effect of motivation and leadership style to employee performance. This research was held at the Office of Industry and Trade of South Sulawesi Province. The sample of this study was 64 respondents. This study is a quantitative research and analysis methods of data using multiple linear regression. The results of this study indicate that the variables of motivations and leadership style to employee performance. In partial leadership style does not significantly affect the performance of employees while variable motivation significantly affect the performance of employees at a significance level of less than 0,05 or 5\%.
\end{abstract}

Keywords: Motivation, Leadership Style, Employee Performance.

\begin{abstract}
Abstrak
Penelitian ini bertujuan untuk menganalisis pengaruh motivasi dan gaya kepemimpinan terhaap kinerja pegawai. Penelitian ini diadakan di Kantor Dinas Perindustrian dan Perdagangan Provinsi Sulawesi Selatan. Sampel penelitia ini yaitu pegawai sebanyak 64 orang responden. Penelitian ini adalah penelitian kuantitatf dan metode analisis data menggunakan regresi linear berganda. Hasil penelitian ini menunjukkan bahwa variabel motivasi dan gaya kepemimpinan berpengaruh secara signifikan terhadap kinerja pegawai. Secara parsial variabel gaya kepemimpinan tidak berpengaruh secara signifikan terhadap kinerja pegawai sedangkan variabel motivasi berpengaruh secara signifikan terhadap kinerja pegawai pada tingkat signifikan kurang dari 0,05 atau 5\%
\end{abstract}

Kata Kunci: Motivasi, Gaya Kepemimpinan, Kinerja Pegawai. 


\section{PENDAHULUAN}

Kepemimpinan merupakan unsur penting dalam suatu perusahaan atau instansi pemerintahan, alasannya karena dengan kepemimpinan yang tidak profesional maka akan berpengaruh terhadap kinerja pegawai. Hal ini sesuai dengan teori yang dikemukakan oleh Thoha (2007:1) bahwa suatu organisasi akan berhasil atau bahkan gagal sebagian besar ditentukan oleh kepemimpinan, sebab pemimpinlah yang bertanggung jawab atas kegagalan suatu pekerjan.

Menurut Ambarwati (2008:12) bahwa kepemimpinan adalah suatu seni atau proses mempengaruhi sekelompok orang sehingga mereka mau bekerja dengan sungguh-sungguh untuk meraih tujuan kelompok. Kemudian kepemimpinan yang dilakukan sangat berpengaruh terhadap peningkatan kinerja. Hal ini sesuai dengan hasil penelitian yang dilakukan oleh Fahmi (2009) yang meneliti pengaruh motivasi dan gaya kepemimpinan terhadap kenerja pegawai. Hasil penelitian yang dilakukan oleh Fahmi yang menemukan ada pengaruh yang signifikan antra kepemimpinan dengan kinerja pegawai.

$$
\text { Pentingnya kepemimpinan }
$$

terhadap kinerja pegawai dalam suatu organisasi lebih banyak sebagai alat motivator sehingga motivasi kerja dijadikan sebagai salah satu faktor yang penting, sebab dengan adanya motivasi kerja yang tinggi maka akan dapat ditunjang oleh adanya peningkatan kinerja pegawai. Oleh karena itu motivasi kerja sangatlah diperlukan terhadap peningkatan kerja pegawai.

Kedudukan dan peranan pegawai sebagai unsur yang bertugas sebagai abdi masyarakat harus menyelenggarakan pelayanan secara adil kepada masyarakat dengan dilandasi kesetiaan dan ketaatan kepada Pancasila dan Undang-Undang Dasar 1945. Untuk dapat melaksanakan tugas dengan baik, maka pembinaan pegawai diarahkan untuk meningkatkan kualitas sumber daya manusia agar memiliki sikap dan perilaku yang berintikan pengabdian, kejujuran, profesional, tanggung jawab, disiplin, etos kerja serta wibawa sehingga dapat memberikan pelayanan sesuai tuntutan perkembangan masyarakat.

Pencapaian keinginan didalam sebuah organisasi, SDM merupakan merupakan salah satu aset yang tidak ternilai harganya karena dapat memberikan konstribusi yang berarti kepada satuan kerja secara efektif, efesien, produktif, dan kompetitif. Oleh kerena itu bagaimana cara untuk mengembangkan, memelihara dan meningkatkan kinerja merupakan salah satu faktor yang perlu dituntut adanya kemampuan yang profesional, berkualitas, dan berkompetensi dalam menjalankan tugasnya.

Ada keterkaitan antara Motivasi dan Gaya Kepemimpinan Terhadap Kinerja Pegawai. Dengan Motivasi dan Gaya Kepemimpinan yang tinggi dimiliki oleh Pegawai dalam bekerja akan menghasilkan kinerja yang lebih tinggi dalam melaksanakan pekerjaannya. Dengan demikian dapat disimpulkan bahwa ada korelasi positif dari Motivasi dan Gaya Kepemimpinan terhadap kinerja pegawai, dimana pegawai yang memiliki kinerja yang baik tentunya akan menghasilkan hasil yang lebih maksimal. Sehingga penelitian ini dilakukan untuk mengetahui faktor yang mempengaruhi kinerja pegawai tersebut. 


\section{TINJAUAN PUSTKA}

\subsection{Motivasi dengan Kinerja Pegawai}

Menurut (Rivai dan Sagala, 2009:873), Motivasi adalah serangkaian sikap dan nilai-nilai yang mempengaruhi individu untuk mencapai hal yang spesifik sesuai dengan tujuan individu. Sikap dan nilai-nilai tersebut merupakan suatu yang invisibel yang memberikan kekuatan untuk mendorong individu bertingkah laku dalam mencapai tujuan.

Penelitian yang dilakukan Hidayat (2007:56) menunjukkan bahwa motivasi kerja pegawai mempunyai pengaruh positif yang signifikan dengan kinerja pegawai. Artinya, motivasi kerja pegawai mempunyai pengaruh positif signifikan terhadap kinerja pegawai. Hasil penelitian ini sesuai dengan penelitian yang dilakukan oleh Hakim (2011) dan Prasetyo (2008) yang menyatakan bahwa gaya kepemimpinan berpengaruh signifikan terhadap kinerja.

\subsection{Gaya Kepemimpinan dengan Kinerja Pegawai}

Menurut Miftah, Thoha (2010:303) gaya kepemimpinan merupakan norma perilaku yang digunakan oleh seseorang pada saat orang tersebut mencoba mempengaruhi perilaku orang lain seperti yang ia lihat. Menurut penelitian yang dilakukan oleh Sopiah (20012:35) dalam penelitiannya menyimpulkan bahwa adanya pengaruh positif antara gaya kepemimpinan terhadap kinerja. Hal tersebut berarti semakin baik cara memimpin seorang pimpinan maka akan semakin mempengaruhi kinerja pegawai. Hasil penelitian ini sesuai dengan penelitian yang dilakukan oleh Hakim (2011) dan Prasetyo (2008) yang menyatakan bahwa gaya kepemimpinan berpengaruh signifikan terhadap kinerja.

\subsection{Kerangka Pikir/ Kerangka Konsep \\ Secara sederhana, kerangka pemikiran dalam penelitian ini ditunjukkan dengan bagan sebagai berikut:}

Hal ini berarti bahwa ketiga faktor yang diteliti ini memiliki hubungan signifikan dan positif, yang didalam formulasi penelitian ini adalah penyatuhan motivasi dan gaya kiepemimpinan terhadap kinerja pegawai yang kerangka fikirnya seperti pada gambar 2.1 berikut ini:

\section{METODE PENELITIAN}

\subsection{Jenis penelitian}

Jenis penelitian yang digunakan yaitu metode deskriptif, metode deskriptif merupakan suatu metode penelitian daka meneliti setatus dari sekelompok manusia, suatu objek, suatu peristiwa pada masa saat ini. Adapun tujuan penelitian deskriptif ini yaitu untuk membuat gambaran, deskipsi atau lukisan secara sistematis, fkatual dan akurat mengenai fakta, sifat serta hubungan antara fenomena yang sedang diselidiki. Penelitian deskriptif merupakan metode penelitian yang digunakan untukmenentukan pengetahuan objek penelitan pada suatu masa tertentu.

\subsection{Analisis Deskriptif}

Analisis deskriptif dalam penelitian ini akan mendeskriptifkan data karakteristik responden berdasarkan jenis kelamin, usia, lama kerja dan tingkat pendidikan. Analisis deskriptif digunakan untuk mengetahui tanggapan responden mengenai nilai variabel penelitian. Analisis deskriptif ditunjukkan melalui dua presentase.

\subsection{Uji Asumsi Klasik}




\subsubsection{Uji Multikolienaritas}

Uji multikolinearitasbertujuan untuk menguji apakah model regresi ditemukan adanya korelasi antar variabel bebas (independen). Model regresi yang baik seharusnya tidak terjadi korelasi diantara variabel independen. Uji mulrikolinearitas dapat dilihat dari nilai Tolerne dan Variance Inflation Facror (VIF). Nilai tolerance yang rendah sama dengan nlai VIF yang tinggi (karena VIF = $1 /$ Tolerance. Nilai cutoff yang umum dipakai untuk menunjukkan adanya multikolinearitas adalah nilai tolerances 0.10 atau sama dengan nilai VIF $\geq 10$. Tingkat kolinearitas yang dapat ditolerir adalah nilai tolerance 0.10 atau sama dengan tingkat multikolinearitas 0.95 (Ghozali, 2011: 105-106).

\subsubsection{Uji Normalitas}

Uji normalitas bertujuan untuk menguji apakah suatu model regresi, variabel pengganggu atau variabel residual memiliki distribusi normal. Model data yang baik adalah berdistribusi normal atau mendekati normal (Ghozali, 2011:160). Untuk melihat data distri usi normal dapat dilakukan dengan memperhatikan normal probability plot pada scatter plot berdistribusi normal.

\subsubsection{Uji Heteroskedastisitas}

Uji Heteroskedastisitas bertujuan menguji apakah dalam metode regresi terjadi ketidaksamaan variance dari residual suatu pengamatan ke pengamatan yang lain. Jika residual satu pengamatan ke pengamatan lain tetap, maka disebut Homoskedastisitas dan jika berbeda disebut Heteroskedastisitas. Model regresi yang baik adalah yang
Homoskedastisitas atau tidak heteroskedastisitas (Ghozali, 2011:139).

4. HASIL PENELITIAN

\subsection{Uji Signifikan Simultan (Uji Statistik F)}

Uji statistik F pada dasarnya untuk menunjukkan apakah semua variabel independen atau bebas yang dimasukkan dalam model mempunnyai pengaruh secara bersama-sama atau simultan terhadap variabel dependen atau trikat. Lalu membandingkan nilai $\mathrm{F}$ hitung $>\mathrm{F}$ tabel, maka $\mathrm{H}_{0}$ ditolak dan menerima HA. Hasilnya dinyatakan bahwa variabel independen secara serentak dan signifikan mempengaruhi variabel dependen (Ghozali, 2019:98).

Tabel 4.40

Uji F

ANOVA $^{\mathrm{a}}$

\begin{tabular}{|c|c|c|c|c|c|c|}
\hline & Model & $\begin{array}{l}\text { Sum of } \\
\text { squares }\end{array}$ & Df & Mean square & $\bar{F}$ & Sig. \\
\hline 1 & $\begin{array}{l}\text { Regression } \\
\text { Residual } \\
\text { Total }\end{array}$ & $\begin{array}{c}15.938 \\
160.062 \\
176.000\end{array}$ & $\begin{array}{c}2 \\
61 \\
63\end{array}$ & $\begin{array}{l}7.969 \\
2.624\end{array}$ & 3.237 & $.000^{\mathrm{b}}$ \\
\hline
\end{tabular}

a. Dependen Variabel: (Y)

b. Predictors: (Costant), (X2), (X1)

Sumber: Hasil output SPSS data primer yang diolah, 2019.

\subsection{Uji Signifikan Parameter Individual (Uji Statistik t)}

Uji statistic $t$ pada dasarnya menunjukkan seberapa jauh pengaruh satu variabel penjelas atau independen secara individual dalam menerangkan variasi dependen. (Ghozali, 2011:98).

Tabel 4.41

Hasil Uji t

\begin{tabular}{|c|c|c|c|c|c|}
\hline \multirow[t]{2}{*}{ Model } & \multicolumn{2}{|c|}{$\begin{array}{l}\text { Unstandardized } \\
\text { Coefficients }\end{array}$} & \multirow{2}{*}{$\begin{array}{c}\begin{array}{c}\text { Standardize } \\
\mathbf{d} \\
\text { Coefficients }\end{array} \\
\text { Beta } \\
\end{array}$} & \multirow[t]{2}{*}{$\mathrm{t}$} & \multirow[t]{2}{*}{ Sig. } \\
\hline & B & \begin{tabular}{|l|} 
Std. Error \\
\end{tabular} & & & \\
\hline $\begin{array}{l}\text { (Constant) } \\
1 \text { MOTIVASI (X1) } \\
\text { GAYA } \\
\text { KEPEMIMPINAN (X2) }\end{array}$ & $\begin{array}{r}37,69 \\
-230 \\
, 265\end{array}$ & $\begin{array}{r}8,985 \\
, 107 \\
, 162\end{array}$ & $\begin{array}{r}-267 \\
, 204\end{array}$ & $\begin{array}{r}4,195 \\
-2,138 \\
2,635\end{array}$ & $\begin{array}{l}, 000 \\
, 107 \\
, 027\end{array}$ \\
\hline
\end{tabular}

Melihat output SPSS hasil coefficients pada uji-t diatas dan membandingkan $t_{\text {hitung }}$ dengan $t_{\text {tabel }}$ sebesar 2,000 yang 
diperoleh dari tabel t dengan $\mathrm{df}=\mathrm{n}-\mathrm{k}-1$ (64-2-1) yaitu 61 dan alpha 0,05. berikut pembahasan uji parsial antara motivasi, gaya kepemimpinan dan kinerja pegawai pada Kantor Dinas Perindustrian dan Perdagangan Provinsi Sulawesi Selatan.

\subsection{Regresi Linear Berganda}

Berdasarkan tabel 4.40, maka diperoleh model persamaan regresi linear berganda sebagai berikut:

$$
Y=37,690-230 \times 1+0,265 \times 2
$$

Persamaan tersebut memberi indikasi hubungan X1 (motivasi) terhadap kinerja (Y) adalah negatif dengan asumsi $\mathrm{X} 2$ (gaya kepemimpinan) konstan, artinya peningkatan motivasi tidak di ikuti peningkatan kinerja pegawai. Sedangkan X2 (gaya kepemimpinan) berdampak poditif terhadap kinerja pegawai dengan asumsi X1 (motivasi) konstan artinya gaya kepemimpinan yang diterapkan akan meningkatkan kinerja pegawai. Bedanya pengaruh X1 terhadap Y adalah 230 satuan dan besarnya bengaruh X2 terhadap Y adalah 0,265 satuan.

\subsubsection{Koefisien Korelsi Berganda}

Hasil print out menyimpulkan bahwa koefisien korelasi diperoleh nilai 0,301, yang mengindikasikan bahwa motivasi dan gaya kepemimpinan secara bersamaan memiliki hubungan yang sangat lemah dengan kinerja pegawai.

\subsection{Koefisien Determinasi}

Kontribusi variabel bebas terhadap naik/turunnya variabel tidak bebas

Tabel 4.42

Hasil Uji Koefisien Determinasi Model Sumarryb

\begin{tabular}{|c||c||c||c||c||}
\hline $\begin{array}{c}\text { Mod } \\
\text { el }\end{array}$ & R & $\begin{array}{c}\text { R } \\
\text { Sque } \\
\text { re }\end{array}$ & $\begin{array}{c}\text { Adjust } \\
\text { ed R } \\
\text { Squere }\end{array}$ & $\begin{array}{c}\text { Std. } \\
\text { Error } \\
\text { of the }\end{array}$ \\
\hline
\end{tabular}

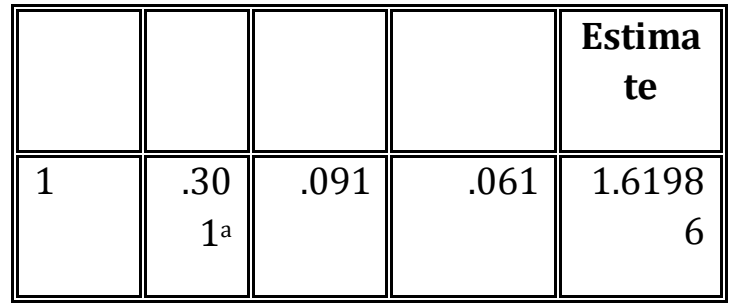

a. Predictors: (Constant), X2, X1

b. Dependent Variabel: $Y$

Sumber: Hasil output SPSS data primer yang diolah, 2019

Berdasarkan tabel 4.42 diatas dapat disimpulkan bahwa koefisien determinasiyang telah disesuaikan (Adjusted $R$ Square) adalah sebesar 0,061 atau 6,1\%. Semakin besar angka Adjusted $R$ Square maka akan semakin kuat hubungan dari dua variabel dalam model regresi. Dapat disimpulkan bahwa 6,1\% variabel kinerja pegawai dapat dijelaskan oleh variabel motivasi dan gaya kepemimpinan. Sedangkan selisihnya 93,9\% lainnya dipengaruhi atau dijelaskan oleh variabel lain yang tidak masuk dalam penelitian ini.

\section{PENUTUP}

\subsection{Simpulan}

Penelitian ini bertujuan untuk mengetahui pengaruh motivasi dan gaya kepemimpinan terhadap kinerja pegawai pada Kantor Dinas Perindustrian dan Perdagangan Provinsi Sulawesi Selatan. rensponden dalam penelitian ini berjumlah 64 orang pegawai. Berdasarkan data yang dikumpulkan dan pengujian yang telah dilakukan terhadap permasalahan dengan menggunakan mode regresi berganda, maka dapat diambil kesimpulan sebagai beriku:

1. Motivasi dan Gaya Kepemimpinan secara simultan berpengaruh dan signifikan terhadap kinerja pegawai pada Kantor Dinas Perindustrian dan Perdagangan Provinsi Sulawesi Selatan. 
2. Motivasi berpengaruh signifikan terhadap kinerja pegawai pada Kantor Dinas Perindustrian dan Perdagangan Provinsi Sulawesi Selatan.

3. Gaya Kepemimpinan tidak berpengaruh signifikan terhadap kinerja pegawai pada Kantor Dinas Perindustrian dan Perdagangan Provinsi Sulawesi Selatan.

4. Gaya Kepemimpinan lebih dominan berpengaruh dibanding Motivasi terhadap kinerja pegawai pada Kantor Dinas Perindustrian dan Perdagangan Provinsi Sulawesi Selatan.

\subsection{Saran}

Berdasarkan kesimpulan yang diuraikan diatas, maka penulis menggunakan saran sebagai berikut:

1. Bagi Kantor Dinas Perindustrian dan Perdagangan Provinsi Sulawesi Selata. Gaya kepemimpinan yang sesuai dengan keinginan instansi pemerintah adalah perlu adanya pengarahan kepada pegawai atau bawahan, serta membantu mereka agar bisa mengatasi kesulitan-kesulitan dan memudahkanmereka dalam menjalankan tugas-tugas sesuai yang telah ditentukan dan juga disiplin kerja harus dibuat sebaik mungkin demi terciptanya suasana kantor yang nyaman serta kondusif. Dengan adanya penelitian ini diharapkan kantor Perindustrian dan Perdagangan Provinsi Sulawesi Selatan, dapat memanfaatkan penelitian ini sebagai bahan pertimbangan agar lebih memperhatikan kebutuhan pegawai terlebih pada mitovasi dan gaya kepemimpinan yang diterapkan untuk meningkatkan kinerja pegawai yang lebih baik.

2. Bagi akademisi
Bagi kalangan akademisi, penelitian ini diharapkan dapat menjadi referensi untuk penelitian-penelitian selanjutnya yang dimiliki tema yang sama yaitu pengaruh motivasi dan gaya kepemimpinan terhadap kinerja pegawai. Penelitian selanjutnya disarankan untuk mengkaji komponen lain selain masalah motivasi, gaya kepemimpinan dan kinerja pegawai yang telah dibahs oleh penulis atau dengan dimensi dan indikator yang berbeda sehingga pengetahuan dan ilmu manajemen sumber daya manusia untuk masyarakat akan semakin berkembang dan bermanfaat serta dapat menghasilkan ide-ide kreatif yang tentunya berguna untuk masa yang akan dating. Penelitian yang selanjutnya juga disarankan untuk mencari ruang lingkup yang lebih luas dari populasi dalam penelitian ini. Sehingga sampel yang digunakan dapat lebih banyak lagi, sehingga dapat memberikan gambaran yang lebih spesifik mengenai motivasi dan gaya kepemimpinan terhadap kinerja pegawai.

\section{DAFTAR PUSTAKA}

Adryanto, Michael. "Mengenali Metode Penelitian 360 Derajat", Artikel dari http://michaelandyanto.wordpress. com/2011/11/09/mengenalipeneli tian-360-derajat/ 
Ambarwati, Dwi. "Analisis Pengaruh Motivasi Kerja, dan Gaya Kepemimpinan Terhadap Kinerja Pegawai Badan Kepegawaian Kabupaten Tulungagung". Journal Otonomi Vol.12, No.1, 2008.

Bangun, Wilson. "Manajemen Sumber Daya Manusia", Erlangga, Bandung, 2012.

Ghozali, "Metode Penelitian, Penyusunan Kuesioner". Dengan program SPSS, Semarang: Badan Penerbit Universitas Diponegoro. 2005.

Hakim Lukmanul. "Pengaruh Gaya Kepemimpinan Terhadap Kinerja Pegawai Negeri Sipil Melalui Motivasi Pada Dinas Perhubungan Palembang" Volume III. No. 3, 2011.

Hasibuan, SP Melayu. "Manajemen Sumber Daya Manusia". Bumi aksara, edisi ketiga. Jakarta, 2012.

Kaertono, Kartini. "Pemimpin dan Kepemimpinan". Raja Grafindo Persada, Jakarta, 2008.

Kreitner, Robert dan Angelo, Knicki. "Perilaku Organisasi".Jilid 2, Salemba Empat, Jakarta, 2005.

Mangkunegara, Anwar Prabu. "Manajemen Sumber Daya Manusia". Rosdakarya, Bandung, 2010.

Mathis, L. Robert dan Jackson, John H. "Manajemen Sumber Daya Manusia". Jilid 1, Salemba Empat, Jakarta, 2009.

Mulyono. "Pengaruh Kesesuaian Kompetensi dan Motivasi Terhadap Kinerja Pegawai Negara Sipil Bagian
Administrasi pada Sekolah Menengah Atas Negeri Kota Malang". Jurnal Manajemen dan Akuntansi. Vol. 1, No. 1, 2012.

Murray, Adela, Islam, Mazharul, Sarros, James and Andrew. "The Impact of Leadership on Workgroup Climate and Performance in a Non-Profit Organization", Development Journal, Vol.33, No.6, 2012.

Nasrullah. "Buku Panduan Penulisan Skripsi" Unismuh Makassar, 2019

Prasetyo, Iis. "Pengaruh Gaya Kepemimpinan Terhadap Kinerja". Jurnal Neo Bisnis, Vol.2, No.2, 2008.

Prawatya, Adi, Dipta dan Raharjo, Toto, Susilo. "Pengaruh Disiplin Kerja dan Budaya Organisasi terhadap Kinerja Karyawan Pabrik Minyak Kayu Putih (PMKP) di Krai Purwodadi". Diponegoro Journal of Managenment. Vol.1, No.1, 2012.

Rivai, Veithzal. "Manajemen Sumber Daya Manusia untuk Perusahaan" Cetakan ke.3, Jakarta:Rajawali Pers, 2010.

Robbins, Stephen P. "Perilaku Organisasi", Jilid 1, Prehalindo, Jakarta, 2001.

Rochaety, Ety. Tresnati, Ratih. Madjid Latief, Abdul. "Metodologi Penelitian Bisnis: Dengan Aplikasi SPSS". Edisi Revisi, Jakarta: Mitra Wacana Media, 2009.

Sofat, Surbhi. "Effect of Motivation on Empoyee Performance and Organization Produktivity". Journal of Aplied Management \& Computer Sience, Vol.1, 2012. 
Sopiah, Andi. "Perilaku Organisasi". Yogyakarta, 2008.

Thoha, Miftah. "Kepemimpinan dalam Manajemen". Jakarta, Raja Grafindo Persada, 2010.

Umam, Khaerul. "Perilaku Organisasi". Pustaka Setia, Bandung, 2010.

Winardi,J. "Manajemen Perilaku Organisasi". Prenda Media Group, Jakarta.

Wirawan. "Evaluasi Kinerja, Sumber Daya Manusia, Teori Aplikasi dan Penelitian". Salemba Empat, Jakarta, 2009. 